\title{
DETERMINATION OF THE CONSTRAINTS FACING CROSSBRED DAIRY CATTLE FARMERS IN MOSSAY AREA (NYALA - SOUTH DARFUR- SUDAN)
}

\author{
${ }^{1}$ Fatima Mahamoud Ahmed, ${ }^{2} \mathrm{Hamza}^{*}$ Abdalla Eltahir Ahmed, ${ }^{3}$ Bhagiel Tyfour Bhagiel ${ }^{4}$ Abass Abdurahman \\ Hussein and ${ }^{2}$ Fathi Abdalla Mohammed \\ ${ }^{1}$ Ministry of Animal Resources, South Darfur State-Sudan \\ ${ }^{2}$ Institute of Molecular Biology (IMB) University of Nyala-Sudan. \\ ${ }^{3}$ College of Agricultural studies, department of animal Production University of Sudan for science and Technology. \\ ${ }^{4}$ College of veterinary science department of animal production, university of Nyala \\ http://doi.org/10.35410/IJAEB.2019.4452
}

\begin{abstract}
The present study was conducted to detect technical and practical obstacles of crossbred dairy cattle breeders in Mossay area (Nyala) and provide recommendation for possible solution. A total of 32 (thirty two) dairy farms in area of the study were surveyed during October to December 2018. Data was obtained by structured questionnaire designed properly to cover the objectives of the study. Also, personal interview with breeders and researchers observations were used. Then, data was processed and analyzed using descriptive statistics (mean, standard deviation, frequencies and percentages) by SPSS (version.11). The results revealed that $57 \%$ of the breeders did not use records. The majority (92\%) of the respondents agreed that feed stuffs raw materials prices were the major hinder and limiting milk production factor in the area of the study. Moreover, (78\%) and (74\%) of the breeders respectively, confirmed that the weak connection between extension authority and the farmers was a real obstacle. Whereas, $(60 \%)$ of them replied that weakness of infrastructure was one of the milk production constraints in area of the study. However, only (23\%) of the breeders claimed that outbreak of infectious diseases was a part of obstacles in area of study. The results elucidated that the most frequent infectious diseases were: blood parasites (babesiosis and Theileriosis) (42.6\%), then brucellosis (22.2\%), Mastitis 22.2\% and Foot and mouth disease 13.2\%. The results revealed that (78\%) of the respondents extremely agreed and (13\%) of them agreed that weak marketing system and brokers control over retail prices were the main constraints facing the farmers in area of the study. Furthermore, $(67 \%)$ of the breeders demonstrated that absence of regulations for milk and milk products quality control has adverse effects on marketing process in area of the study. The study detected some managerial, technical, extension, hygienic and marketing constraints facing the breeders in area of the study and suggested packages of solutions included within the recommendations.
\end{abstract}

Keywords: Constraints, milk production, dairy farms owners, Mossay, Nyala.

\section{INTRODUCTION}


Although Sudan has multiple natural resources (aquatic, animal, and fish), studies indicate that dairy and dairy products rank high in the list of imported agricultural food commodities and occupy a huge balance of payments. FAO estimates that milk produced in Sudan is estimated at 7.1 million tons per year.

Indigenous cattle breeds in Sudan particularly (Butana and Kenana) provide the majority of milk supply for domestic consumption beside their adaptability and the ability to withstand the inconvenient and adverse environmental conditions and resistance of endemic diseases (Hamza et al, 2015). Those dairy breeds under improved management at the research stations can produce more than $1500 \mathrm{~kg} /$ lactation, (El-Habeeb, 1991 and Musa et al, 2005). However, still the milk produced from the indigenous dairy breeds not fill the gap of raw milk shortage, therefore, efforts have been directed towards increase production(genetic improvement) of indigenous dairy cattle through selection and cross breeding, as crossbreeding is considered as a quick way of increasing performance of low productive tropical breeds, (Hassan and Khan, 2013).

South Darfur is one of the richest states in Sudan with livestock. Although most cattle are owned by traditional breeders and nomadic herders, the abundance of dairy products is seasonal. In recent years, in South Darfur state (Nyala) it is a common practice using crosses of local breeds with exotic high milking breeds to meet the continuous milk demand of Nyala city which witnessed heavy migration last decade due to the conflicts and tribal wars. It is well documented that these crosses produce better than local types, (McDowell, 1985). However, such type of cattle needs high level of management to ensure profitable milk yield. Unfortunately, a recent study revealed that $45 \%$ of owners of crossbreed farms in this area did not keep records and also a complete absence of data and information concerning productive and reproductive performance traits, nutritional status and health care and scientific management were observed, (Hamza et al, 2015). Therefore, the present work was prepared to determine the constraints facing crossbreed dairy cattle farmers in Nyala (South Darfur State-Sudan) and suggest the possible solution packages.

\section{MATERIALS AND METHODS}

\section{Area of the study:}

The study was conducted in Nyala (South Darfur state -Sudan), mainly in Mossay. (Mossay is a suburb of Nyala located about 9 kilometers Southern-East to Nyala) dairy farms and also the survey covered other dairy farms around Nyala during October to December 2018. This area is a center gathering camps of dairy farms using crossbred dairy cattle. These dairy farms established more than 20 years ago and contributed effectively in supplying milk demand of Nyala, slides 1 and 2 show individual dairy farms from which data was taken.

\section{DATA COLLECTION}

The survey was conducted through a questionnaire and guided interviews with dairy farm owners in Mossay. In this study a total of 32 (thirty two) dairy farms were covered.

A set of detailed structured questionnaire was prepared and used to collect information from dairy farm owners the interview conducted over single visit. Some of the information collected during interviews was supported by observation. 
Vol. 4, No. 05; 2019

ISSN: $2456-8643$

\section{STATISTICAL ANALYSIS}

The SPSS statistical computer software (SPSS for windows, release 15.0, 2006) was used to analyze the data. Results are represented mainly in the form of descriptive tabular summaries.

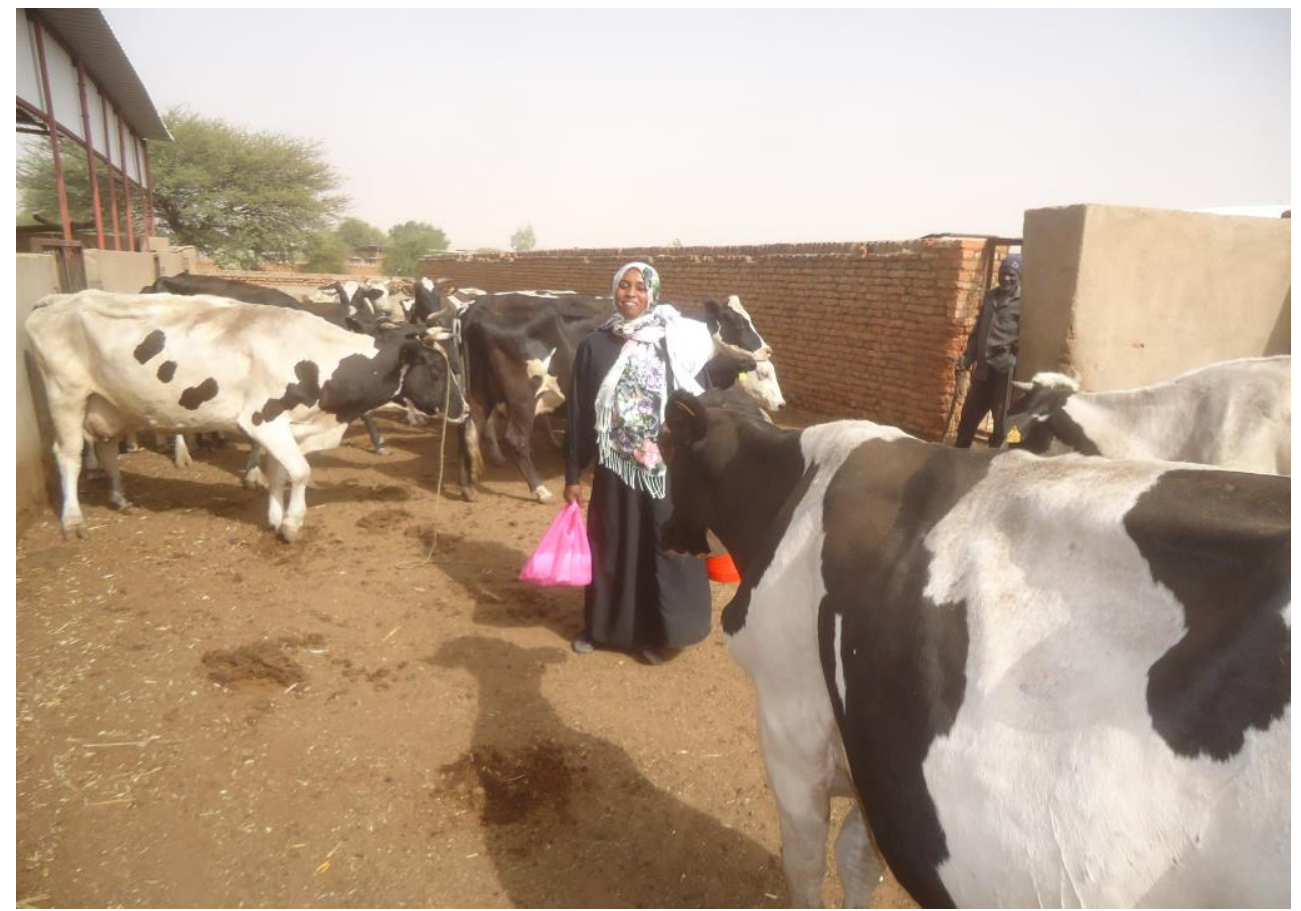

Plate1. Dairy farm in Mossay

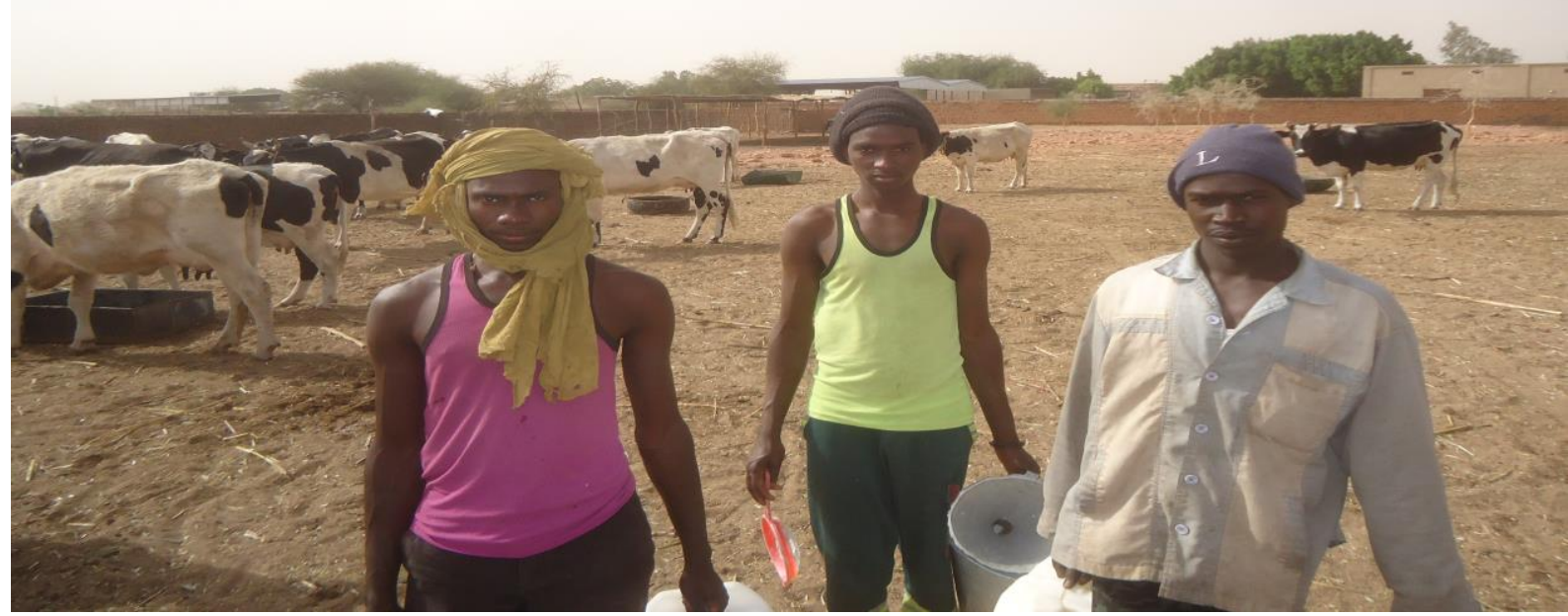


Plate 2. Crossbred dairy cattle farm, Mossay area, South Darfur- Sudan.

\section{RESULTS AND DISCUSSION}

Table (1) demonstrates keeping reports among breeders in area of the study. The results revealed that the major number of the farmers did not keep records, even those who claimed that they use records they just record milk yield and usually record it in paper sheets which are not permanent and liable to loss and damage. The present results were in line with those obtained by (Hamza et al, 2015); they found that (45\%) of the dairy farmers in Mossay area did not keep records. Also, (Humam, 2011) found that (34\%) of crossbred dairy farmers in Sharg Elneel -Khartoum keep records. For sure, recording system in dairy farms is considered to be one of the essential tools of effective farm management. Absences of records affect the right decisions in the dairy farm. However, financial records are useful in analyzing previous performance while keeping health records decrease health hazards and assist in control and treatment of infectious diseases, (Delorenzo and Thomas, 1996) and (Babiker, 2007).

Table (1) keeping records

\begin{tabular}{|l|l|}
\hline Keeping records & Percentage \% \\
\hline Yes & 42.6 \\
\hline No & 57.4 \\
\hline
\end{tabular}

Fig (1) illustrates the rising prices of feedstuffs in area of the study. The results showed that the majority $(78 \%)$ of the respondents were extremely agreed that rising prices of feedstuffs raw materials was a major hinder. The present study is in full agreement with (Mohammed et al, 2014) who conducted a survey to assess Kuku dairy cooperative production system; they found that rising feed prices accounted for $(78.7 \%)$ of dairy production constraints for dairy farmers in kuku area (Khartoum state). Also, (Hamza et al, 2015) reported that feedstuff cost represented (15\%) of constraints limiting dairy production in Mossay area.

The rise in animal feed prices, particularly cereals, has risen sharply globally, peaking in year 2008 , which has had a major impact on the whole dairy production chain, due to competition in feed resources and feed prices, (Alqaisi et al. 2011).

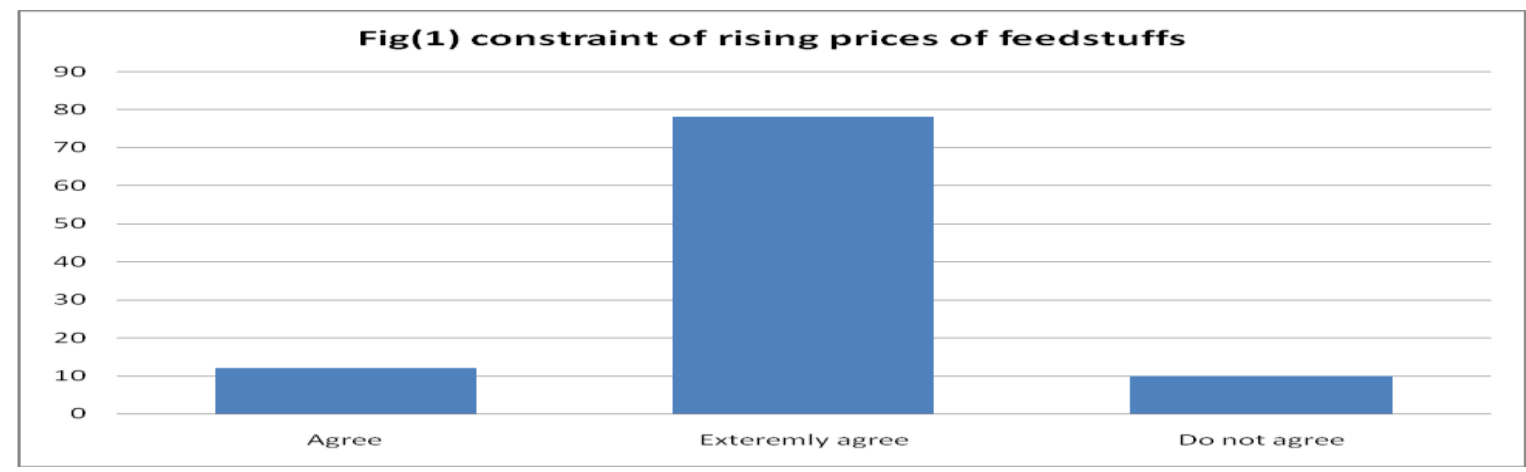


Figures(2and3) represent constraints associated with livestock extension, veterinary services and dairy farmers training in area of the study. It was found that $(78 \%)$ and $(76 \%)$ of the respondents respectively extremely agreed that lacking of livestock extension and veterinary services beside training of dairy cattle breeders were big obstacles facing dairy farmers in area of the study. This weakness in the relationship between breeders in the area of the study and the veterinary extension authority is due to the weak link between the Ministry of livestock and the ineffectiveness of the department of veterinary extension (researcher observation). The livestock extension education plays an important role to empower the farmers with appropriate technological knowledge and skills through various extension education and training programme. These results coincided with those demonstrated by (Yonnas, 2019) who investigated the challenges and opportunities of dairy value chain development in Ethiopia; they detected inadequate extension and training services for dairy farmers in Ethiopia and also, they concluded ; training in milk handling and marketing, farm management and dairy production efficiency are not always available to the Ethiopian dairy farmers.

The constraints related to lack of infrastructures are shown in fig (4). It was observed that (80\%) of the dairy farmers answered that the lack of infrastructures considered as a real obstacle bother them. Lack of paved roads that link the production areas to consumption and means of transport with good specifications, besides lacking cooling facilities are the most important constraints facing dairy sector in Sudan, (workshop on dairy production problems and solutions, 2007).

This finding was in line with those reported by (Yonnas, 2019) who found that spoilage (lack of milk collecting facilities), vertical integration, absence processing plant, inadequate permanent trade routes, ineffectiveness and inadequate infrastructural and institutional set-ups, are the major challenges for dairy production in Ethiopia.

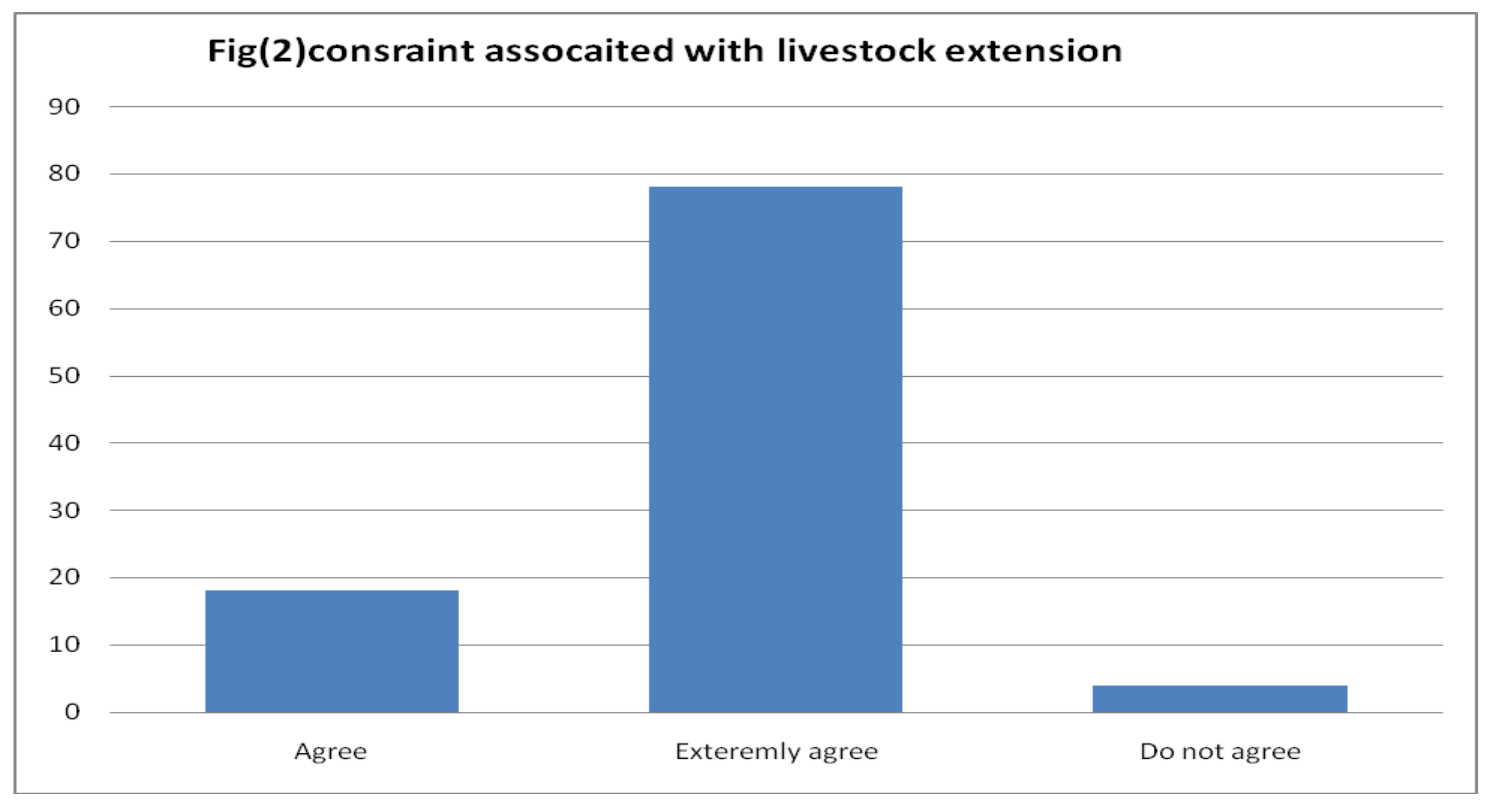



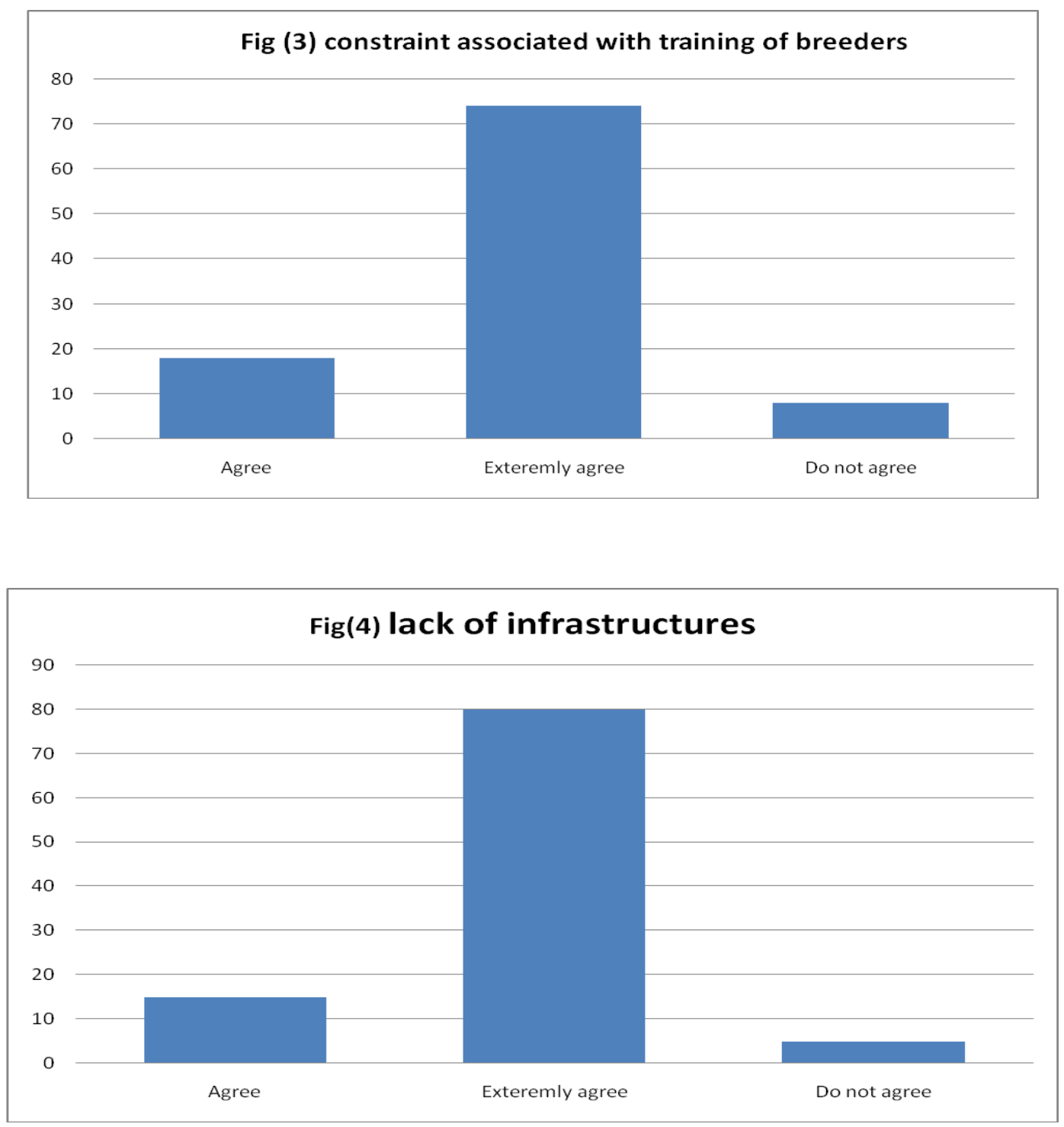

The most frequent diseases in area of the study are presented in fig (5). It is well obvious that blood parasites (mainly babesiosis and theileriosis) was the most frequent (45\%) diseases in area of the study, then brucellosis and mastitis each represented (25\%). Our results were in agreement with findings obtained by (Hamza et al, 2015) they found that about (20\%) of the respondents in Mossay area claimed that prevalence of diseases was the major obstacle.

Moreover, (Babiker, 2007) evaluated the management and health aspects of dairy farms in Khartoum state and recorded (43.4\%) for blood parasites in the dry summer and (56.6\%) during wet summer. Similarly, (Yonnas, 2019) demonstrated that poor animal health and management 
are major constraints of dairy development in Ethiopia which cause poor performance across all dairy production systems.

Constraints associated with marketing are deposited in Fig (7). The majority (75\%) of dairy breeders in Mossay area were strongly agreed that poor dairy marketing system is one of the hinder packages that limiting dairy production development in area of the study. Similar data was also drawn by (Yonnas, 2019) he concluded that constraints to the development of livestock sector in general and dairy in particular in Ethiopia includes many hinders among them poor market infrastructures.
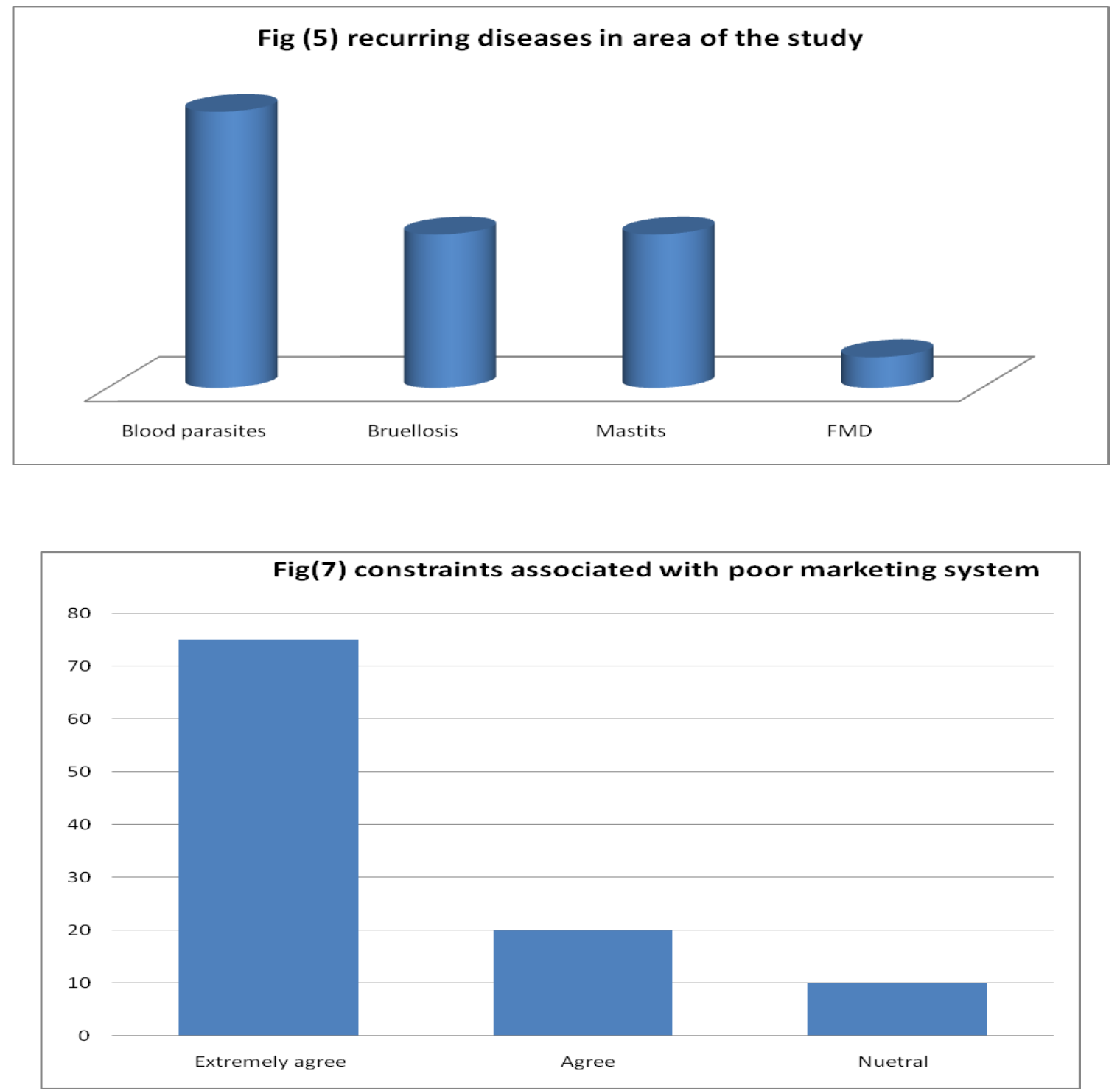

\section{CONCLUSION}


The present study elucidated that crossbred dairy cattle farmers in area of the study facing several technical, productive, marketing and administrative constraints, these constraints limited the production of such good dairy breeds rising in area of the study ;consequence, induced big financial losses for the breeders.

\section{REFERENCE}

Alqaisi S, O, Ndambi, O and Hemme, T. (2011). Global view on feed cost and feed efficiency on dairy farms. All about Feed Magazine. 2. 12-15.

Babiker IA (2007). A case study of dairy camps in Khartoum State, Management and health aspects. Research Journal of Agriculture and Biological Sciences, 3: 8-12.

Delorenzo MA and Thomas CV (1996).Dairy records and models for economic and financial planning. Journal of Dairy Science, 79: 337-345.

El-Habeeb, E. A. (1991). Variation in reproductive and milk production traits in Butana and Kenana dairy cattle in the Sudan. M.V.Sc. Thesis, University of Khartoum-Sudan.

Hamza A.E, Eltahir S.S, Huiam M.E. and Makarim A.G, 2015. A study of management, husbandry practices and production constraints of cross-breed dairy cattle in south Darfur state (Sudan). Online J. Anim. Feed Res., 5(2): 62-67. Science line/Journal homepages: http://www.science-line.com/index/; http://www.ojafr.ir.

Hassan, F. and Khan M. S. (2013). Performance of Crossbred Dairy Cattle at Military Dairy Farms in Pakistan. The Journal of Animal \& Plant Sciences, 23(3): 705-714.

Humam A.A, (2011). Effect of Husbandry Practices on Milk Production in Dairy Farms in Sharg EL Neel Locality, Khartoum, M.Sc. thesis, Faculty of Animal Production, University of Khartoum.

McDowell, R.E. (1985). Crossbreeding in tropical areas with emphasis on milk, health and fitness. Journal of Dairy Science, 68: 2418-2435.

Mohamed, H., El-Zubeir, Ibtisam and Fadlelmoula, Abdul-Aziz. (2014). Management, husbandry and milk production in dairy farms in Khartoum State. University of Khartoum. Journal of Veterinary Medicine and Animal Production. 5. 38-52.

Musa. L.M. Ahmed M.K, Peters K.J Zumbach, B. and Gubartalla K.A. (2005). The reproductive and milk performance merit of Butana cattle in Sudan. Archives of Animal Breeding, 48:445-459.

Workshop on dairy production problems and solutions, Khartoum, Sudan, (2007).

Yonnas A, (2019). Review on the Challenges and Opportunities of Dairy Value Chain Development in Ethiopia; International Journal of Business Management and Technology, 3 (2): 2581-3889. 